\title{
Silane as adhesion promoter in damaged areas
}

\section{Cecilia Deyá}

CIDEPINT (Centro de Investigación y Desarrollo en Tecnología de Pinturas), CONICET Researcher, Calle 52 entre 121 y 122, B1900 AYB, La Plata, Argentina

\section{A R T I C L E I N F O}

\section{Article history:}

Received 2 June 2014

Received in revised form 2 September 2015

Accepted 3 September 2015

\section{Keywords:}

Thin films

Coatings

Corrosion tests

Scanning electron microscopy

\begin{abstract}
A B S T R A C T
Silanes have been studied as adhesion promoters between metals (aluminum, galvanized steel and steel) and paints such as polyurethanes.

The objective of this work was to study $\gamma$-glycidoxypropyltrimethoxysilano (glymo) as adhesion promoter between sandblasted steel and one water-based epoxy paint formulated in the laboratory. In some cases, the silane film was doped with sodium phosphate or sodium benzoate, and in other cases, glymo or extra epoxy resin were incorporated as part of the paint formulation.

The performance of the metal-glymo-paint system was studied by electrochemical noise technique and accelerated tests (salt spray cabinet and humidity chamber). Dry and wet adhesions were also determined.

The results showed that the incorporation of $\gamma$-glycidoxypropyltrimethoxysilane as pretreatment or in paint formulation does not enhance paint adhesion in undamaged areas. However, when the painted area was damaged, the incorporation of silane in the paint or doped silane in the pretreatment enhances paint performance in these areas.
\end{abstract}

(c) 2015 Elsevier B.V. All rights reserved.

\section{Introduction}

The adhesion of the paint on a metal substrate depends, mainly, on the roughness of the substrate and its degree of cleanliness (fatless, oxides lefts, etc.). In order to achieve a good degree of adhesion, even under wet conditions, sandblasted is being used. However, this process is not good enough and, sometimes, adhesion promoters are needed. Chromate compounds were one of these promoters with the advantage that, as pretreatment, they also work as an anticorrosive compound [1,2]. This pretreatment had been used for very long time with very good results but chromates were forbidden due to their toxicity [3].

Silanes are being studied as adhesion promoters. Their chemical structure is $\mathrm{R}-\mathrm{OSi}-\left(\mathrm{OR}^{\prime}\right)_{3}$, being $\mathrm{R}$ an organofunctional group not hydrolysable and $\mathrm{R}^{\prime}$ an organic group, able to react by hydrolysis $[4,5]$. The general mechanism to enhance adhesion is due to the formation of a covalent bond between silanol, resulted from the hydrolysis of silane, and the oxyhydroxide layer present on the substrate. In this reaction, the $\mathrm{R}^{\prime}$ group is loss as an alcohol. On the other hand, the selection of $R$ group depends on its compatibility with the resin of the anticorrosive paint as this

\footnotetext{
E-mail address: estelectro2@cidepint.go.ar
}

group might react with the resin forming another covalent bond [6,7].

Several silanes have been studied as adhesion promoters between metallic substrates (galvanized steel, steel, aluminum, copper) and paint such as polyurethanes and epoxy [8-10]. In general, silanes can be incorporated in paint technology as a pretreatment to the substrate or in the paint formulation $[11,12]$. Besides, it is possible to dope silanes with corrosion inhibitors extending the protection afforded by the paint. Among the inhibitors that can be used, cerium and lanthanum ions are being studied [12-15].

The objective of this work was to study $\gamma$ glycidoxypropyltrimethoxysilane (glymo, Fig. 1) as adhesion promoter doped with different well-known corrosion inhibitors. The inhibitors studied were sodium salts of phosphate and benzoate ions [16] that were incorporated with the silane as pretreatment. After the pretreatment, the panels were painted with water-based epoxy-polyamidoamine coating with zinc phosphate as anticorrosive pigment [17]. As control, panels without pretreatment were also painted.

Besides, some steel panels without pretreatment were protected with paint similar to the above mentioned one, but glymo or extra epoxy resin were added as part of paint formulation. In these cases, the crosslinking degree could be affected as the epoxy groups 


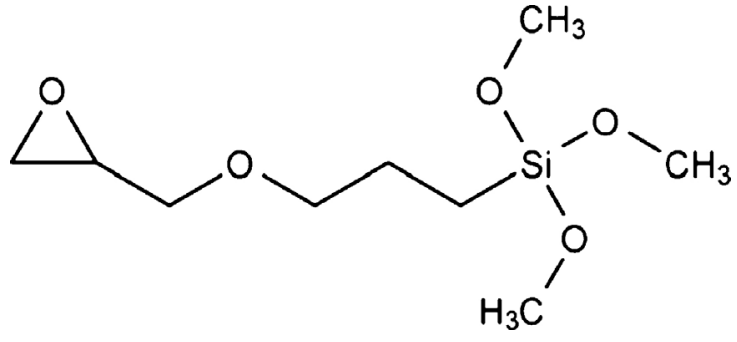

Fig. 1. Glymo.

present in the silane could react with the amine curing agent during the paint curing process.

\section{Experimental}

\subsection{Preparation of the pretreated panels}

A $1 \%$ by weight $(w / w)$, water solution of glymo (Camsi-X) was prepared and stirred for $1 \mathrm{~h}$. Afterwards, a "flash rust" inhibitor (SER AD FA 179, supplied by SASOL Servo BV) was added in a final concentration of $0.5 \% \mathrm{w} / \mathrm{w}$.

The substrate employed was SAE 1010 steel with a roughness $R_{t}$ (peak-to-valley) of $7.60 \mu \mathrm{m}$, obtained by emery paper. A set of panels were dipped in the glymo solution for $20 \mathrm{~s}$, removed at $32 \mathrm{~cm} \mathrm{~min}^{-1}$ and cured at $100^{\circ} \mathrm{C}$ for $1 \mathrm{~h}$. This procedure was done twice.

In the case of the doped silane, a certain amount of sodium salt (purchased from Anedra) up to a concentration of $0.08 \% \mathrm{w} / \mathrm{w}$ was added to the glymo solution after the addition of the "flash rust" inhibitor. These suspensions were stirred until complete dissolution of the salt. The salts employed were: sodium acid phosphate and sodium benzoate.

A panel without pretreatment was used as control.

In Table 1 the paint composition and the nomenclature of the samples can be seen.

The steel pretreated surfaces were observed by scanning electron microscopy (SEM). The films' composition was studied by energy dispersive X-ray analysis (EDX).

\subsection{Tests on pretreated panels}

A Potentiostat/Galvanostat EG\&G PAR Model 273A plus SOFTCORR 352 software was employed to obtain the polarization curves of the pretreated samples. A platinum grid was used as counterelectrode and a saturated calomel electrode (SCE) was the reference electrode. The swept amplitude was $\pm 250 \mathrm{mV}$ from the open circuit potential and the scan rate $0.5 \mathrm{mV} \mathrm{s}^{-1}$.

The curves were done after $1 \mathrm{~h}$ of immersion in $\mathrm{NaCl} 0.5 \mathrm{M}$. The area under study was $0.45 \mathrm{~cm}^{2}$, delimited employing bee wax.

\subsection{Preparation of painted panels}

Panels sandblasted up to Sa21/2 degree(SIS 055900 ), roughness $R_{t}=22 \mu \mathrm{m}$, were first degreased with toluene and then pretreated with glymo as before. In these cases, as the surface roughness was higher the pretreatment procedure was repeated three times.

After pretreatment, the panels were painted with a water-based paint that contained $3.6 \%$ by volume of zinc phosphate (supplied by SNCZ) as anticorrosive pigment. The complementary pigments were barium sulfate (1.6\%), titanium dioxide (2.4\%), talc $(2.3 \%)$ and mica $(2.0 \%)$. The film forming material of the paint was an epoxy resin (Hz340, Huntsman) and a polyamidoamine curing agent (Py340, Huntsman) that should be mixed just before painting.

Control panels, without pretreatment, were also painted.

A second set of panels was painted with the addition in paint formulation of $1 \%$, by volume, of glymo previously hydrolyzed for $1 \mathrm{~h}$ in distilled water.

A third set of panels was painted with $1 \%$, by volume, of extra epoxy resin in paint formulation.

Paints were applied by brush until a final dry thickness of $90 \pm 5 \mu \mathrm{m}$. Painted panels were kept indoors for 15 days before tested.

\subsection{Tests on painted panels}

\subsubsection{Ionic resistance}

The electrochemical cells employed to evaluate the ionic resistance of painted steel were constructed by delimiting $3 \mathrm{~cm}^{2}$ circular zones on the painted surfaces. An acrylic tube $(5.0 \mathrm{~cm}$ high) was placed on the specimen and filled with $0.5 \mathrm{M} \mathrm{NaCl}$. The resistance between the coated steel and a platinum electrode was measured employing an ATI Orion (model 170) conductivity meter at $1000 \mathrm{~Hz}$.

\subsubsection{Electrochemical noise measurements (ENM)}

The cell for ENM was constituted by two nominally identical electrodes (painted panels) and a reference electrode (SCE). The edges of the panels were blanked off leaving $47 \mathrm{~cm}^{2}$ of the painted surface exposed to $0.5 \mathrm{M} \mathrm{NaCl}$. A low value resistor (1.2 $\Omega$ ) was placed between the two panels and current noise was measured as the fluctuation in voltage across the resistor [18]. The three electrodes were in the same container in order to control the effect of temperature fluctuations. Data were acquired with a NICOLET 310 digital oscilloscope and the corresponding software 310RSWFT. Adequate filtering was provided just to eliminate undesirable signals [19-21]. The sensitivity of the measuring device in the E-scale was $100 \mu \mathrm{V}$ and $100 \mathrm{nA}$ in current measurements. The sampling frequency was $5 \mathrm{~Hz}$, which is commonly used to study corroding systems [19-21]. Data were collected during 800 s. Each set of data was controlled to verify its normal distribution [22]. Statistical analysis of each time series was performed and the noise resistance $\left(R_{\mathrm{n}}\right)$ was calculated as the quotient $R_{\mathrm{n}}=\sigma_{\mathrm{E}} / \sigma_{\mathrm{j}}$, being $\sigma_{\mathrm{E}}$ the dispersion of the potencial values and $\sigma_{\mathrm{j}}$ the dispersion of the $\mathrm{j}$ values [19-21]. Although the mean values of raw data were plotted, the

Table 1

Paint formulation and nomenclature of the samples.

\begin{tabular}{|c|c|c|c|c|}
\hline \multirow[t]{2}{*}{ Paints } & \multicolumn{4}{|c|}{ Paint components (\% by volume) } \\
\hline & Pigment formula & Resin + curing agent $(1: 1)$ & Water & Extra epoxy resin \\
\hline A (Control paint) & 13.6 & 65.1 & 21.3 & - \\
\hline B (Glymo in paint) & 13.6 & 64.4 & 21.0 & - \\
\hline C (Glymo in pretreatment) & 13.6 & 65.1 & 21.3 & - \\
\hline $\mathrm{D}$ (Extra epoxy resin) & 13.6 & 64.7 & 21.0 & 0.7 \\
\hline $\mathrm{E}$ (Glymo in pretreatment doped with $\mathrm{Na}_{2} \mathrm{HPO}_{4}$ ) & 13.6 & 65.1 & 21.3 & - \\
\hline $\mathrm{F}$ (Glymo in pretreatment doped with $\mathrm{NaCOOC}_{6} \mathrm{H}_{5}$ ) & 13.6 & 65.1 & 21.3 & - \\
\hline
\end{tabular}


d.c. trend was removed to perform $R_{\mathrm{n}}$ calculation by the moving average removal procedure described by Tan et al. [23].

\subsubsection{Salt spray and humidity chambers}

Painted panels were placed in the salt spray chamber (ASTM B117 [24]) and in the humidity chamber (ASTM D2247 [25]) to evaluate rusting (ASTM D610 [26]) and blistering (ASTM D714 [27]) degrees. Evaluation was done after 1000,1540 and $2600 \mathrm{~h}$ of exposure, in the salt spray chamber and after 600 and $2600 \mathrm{~h}$ in the humidity chamber.

In order to expose the metal directly to the aggressive environment, a scribe mark was done on the painted surfaces. The creepage from the scribe was evaluated employing the standard ASTM D1654 [28] after $1000,1540,2600 \mathrm{~h}$ of exposure in the salt spray chamber.

\subsubsection{Adhesion}

Dry adhesion of the paints was determined by the tape test (ASTM D3359 [29]) after curing. Wet adhesion was determined after 1000 and $1320 \mathrm{~h}$ of exposure in the salt spray chamber also by the tape test method.

\section{Results}

\subsection{Film characterization}

The pretreated steel surface, observed by SEM, seemed to have drops on it due to accumulation of silanes and a thin film of silane underneath the drops. This film followed the emery paper lines on the metal. Fig. 2 showed, as example, the microphotograph of the pretreated steel with the silane doped with sodium benzoate; the dopant was detected as sodium. The film, generally homogenous, has some holes on it $(<5 \mu \mathrm{m})$. The addition of dopants to the silane film did not modify the structure formed by glymo.

\subsection{Tests on pretreated samples}

Tafel curves showed that in any case steel is under passive conditions as the corrosion currents increased as overpotential did; the differences between the samples and control are not significant. The anodic current density of the doped pretreated steel was, after $1 \mathrm{~h}$ of immersion, higher or similar to the naked steel but lower than the glymo-pretreated without dopant, which is the highest one. Cathodic currents showed that the films do not have barrier properties, as the current varies with the overpotential instead of being constant. This would be the case if a limited current was present due to the oxygen reduction reaction, which is controlled by diffusion.

These results, shown in Fig. 3, indicated that the anticorrosive protection afforded by the film is not important, even in the presence of the anticorrosive dopants.

\subsection{Tests on pretreated painted steel}

\subsubsection{Ionic resistance $\left(\mathrm{R}_{i}\right)$}

The ionic resistance of all the samples increased, in general, along the test due to the blocking of pores but the values were smaller than $10^{4} \mathrm{k} \Omega \mathrm{cm}^{2}$ (Fig. 4). $R_{\mathrm{i}}$ values evolution against time of systems A and B as well as $C$ had the same general tendency. In these cases, the initial ionic resistance values were around $0.2 \times 10^{4} \mathrm{k} \Omega \mathrm{cm}^{2}$, and they were almost constant during the whole tests.

Paints D and F had initial values of $R_{\mathrm{i}}$, around $10^{5} \mathrm{k} \Omega \mathrm{cm}^{2}$, two orders of magnitude higher than the ones of the other panels at this time of test. These initial high values of $R_{\mathrm{i}}$ indicate an important
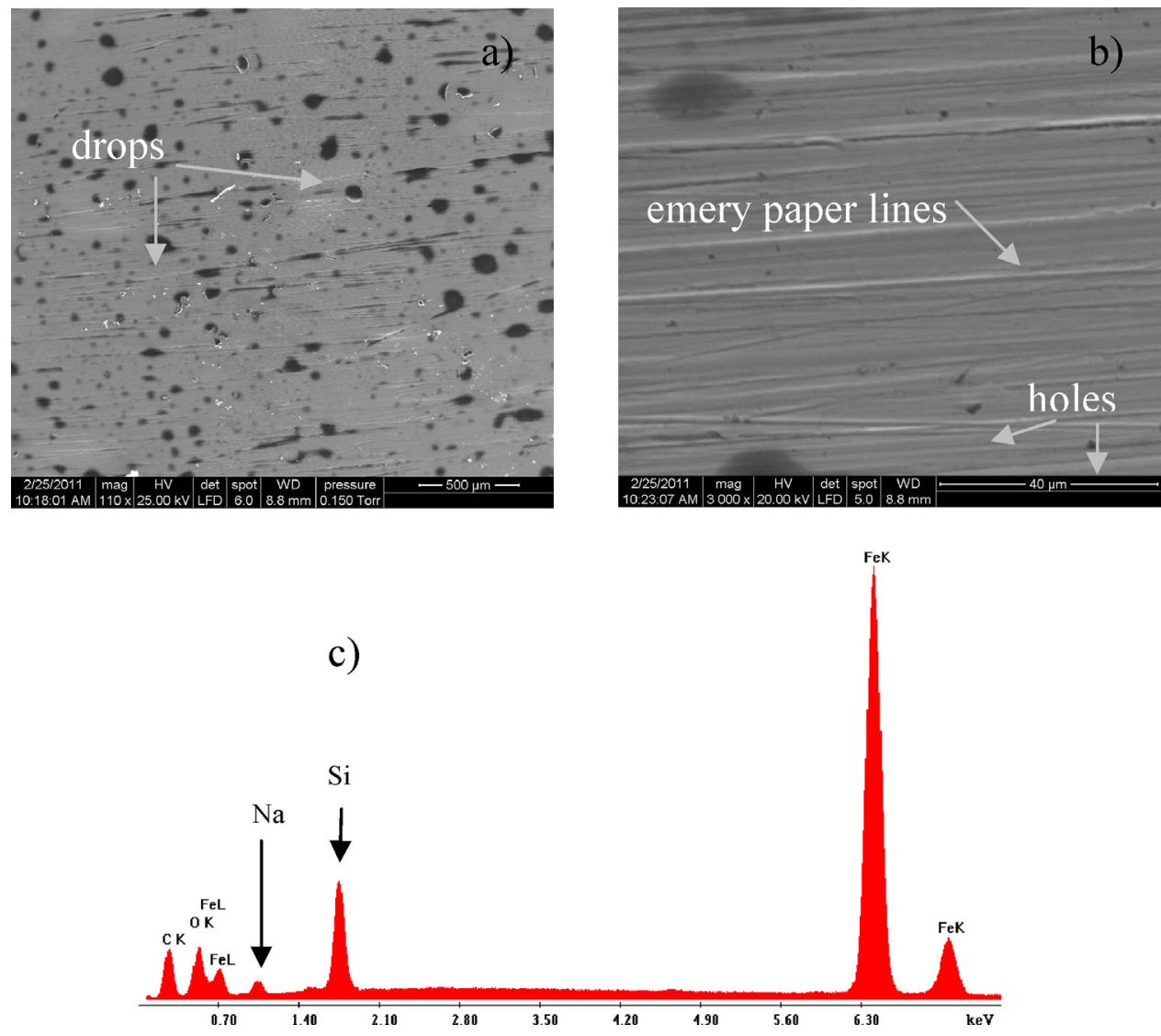

Fig. 2. Scanning electron microscopy of the steel panels pretreated with sodium benzoate-glymo solution. (a) $110 \times$, (b) $3000 \times$, (c) EDX spectra. 


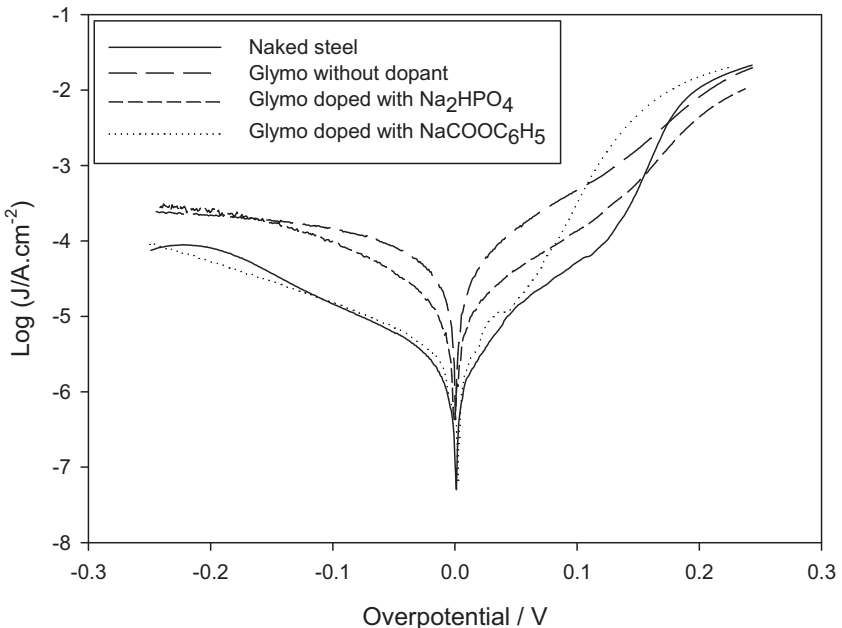

Fig. 3. Polarization curves of the steel pannels.

initial barrier protection but, as water entered across the coating (paint + silane film), $R_{\mathrm{i}}$ dropped reaching, after $72 \mathrm{~h}$ of immersion, the values of the other samples.

The addition of extra epoxy resin to the paint increased its barrier properties, as the $R_{\mathrm{i}}$ was the highest one up to 100 days of immersion (panel D).

In every case, several peaks appeared along the test. These peaks are due to the pores formed in the coating that diminish the resistance while a later blocking of these pores by corrosion products increase the resistance values.

In the case of the panels $\mathrm{E}$, containing $\mathrm{Na}_{2} \mathrm{HPO}_{4}$ in the pretreatment, their behavior was similar to the above mentioned systems but after 83 days of test, no repassivation occurred and the $R_{\mathrm{i}}$ values drop significantly. This may be due to the lixiviation of $\mathrm{Na}_{2} \mathrm{HPO}_{4}$ and the appearance of voids in the coating that allow the entrance of the aggressive species.

\subsubsection{Electrochemical noise measurements (ENM)}

The corrosion potential of the painted panels diminished almost steadily along the test (Fig. 5). Systems A, B and C reached values lower than $-0.5 \mathrm{~V}$ after 25 days of immersion. Systems D, E and $F$ reached this value almost at the end of the test period. Several oscillations appeared on the corrosion potential values due to the

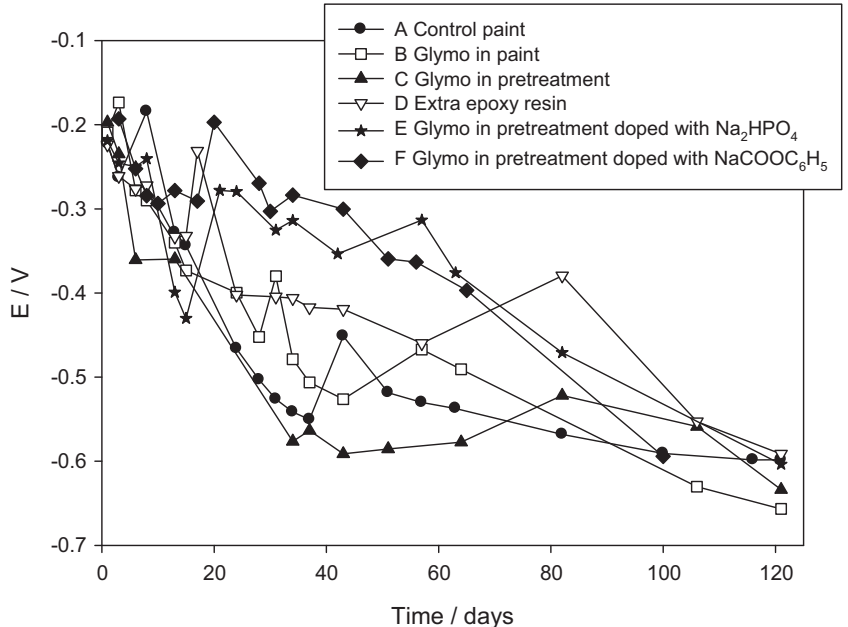

Fig. 5. Corrosion potential of the painted panels against time.

instability of the surface (formation of pores-blocking-formation of new pores).

The coupling current $(J)$ values oscillations were more important at the beginning of the test. These oscillations in $J$ values were in accordance with the instability of the processes occurring on the surface (Fig. 6). The instability of the surface and the inhomogeneities of the panels were more important in the case of panels $\mathrm{A}, \mathrm{B}$ and $\mathrm{C}$.

The noise resistance values of the painted steel (Fig. 7) varied along the test but, in general, the values were less than $1 \mathrm{k} \Omega \mathrm{cm}^{2}$. Some peaks appeared after around 8-15 days of immersion due to the instability of the surface that causes an increment in $\sigma_{\mathrm{e}}$ or a decrease in $\sigma_{\mathrm{j}}$ values. These peaks had values around $3 \mathrm{k} \Omega \mathrm{cm}^{2}$ and they can be related with the repassivation of the painted substrate. Other peaks appeared in the cases of $\mathrm{D}, \mathrm{E}$ and $\mathrm{F}$ with higher values $\left(59 \mathrm{k} \Omega \mathrm{cm}^{2}\right.$ after 82 days, $22 \mathrm{k} \Omega \mathrm{cm}^{2}$ after 57 and $19 \mathrm{k} \Omega \mathrm{cm}^{2}$ after 20 days of immersion, respectively), indicating further repassivation.

\subsubsection{Salt spray and humidity chambers}

In the salt spray chamber, the doped systems $\mathrm{E}$ and $\mathrm{F}$ and the one with extra epoxy resin (D) presented corrosion points after $1000 \mathrm{~h}$ of exposure. Only paint $\mathrm{D}$ presented blisters at that time.

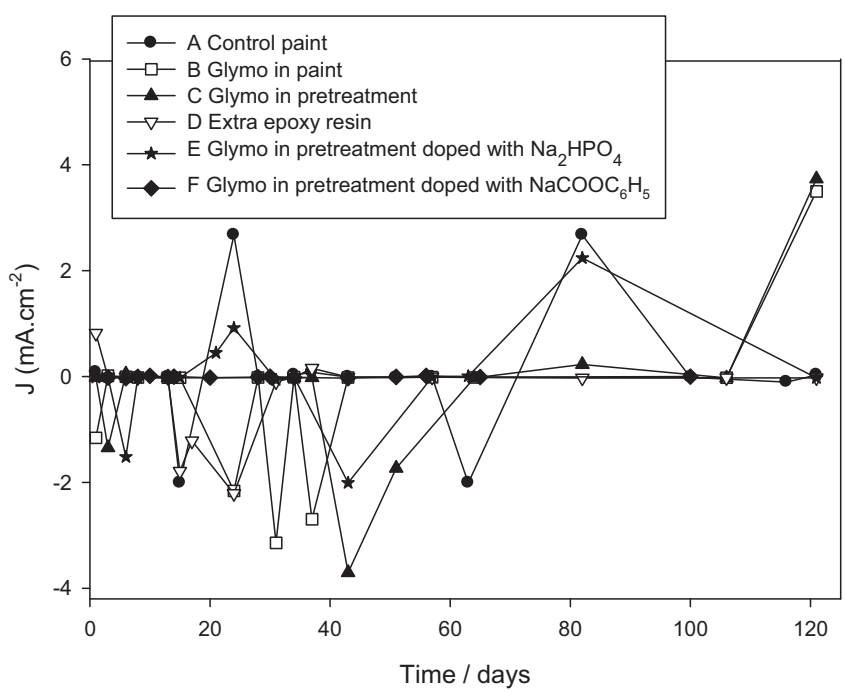

Fig. 6. Corrosion coupling current of the painted panels against time.

Fig. 4. Ionic resistance of the painted panels against time. 


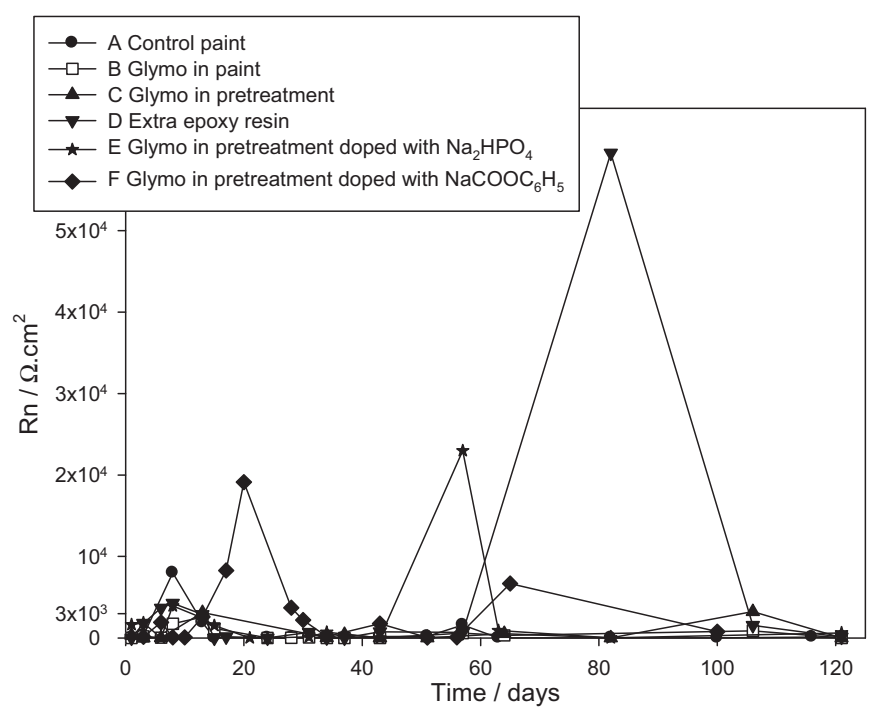

Fig. 7. Noise resistance of the painted panels against time.

Table 2

Rusting (ASTM D610) and blistering (ASTM D714) degrees of painted panels after the salt spray test (ASTM B117).

\begin{tabular}{|c|c|c|c|c|c|c|}
\hline \multirow[t]{3}{*}{ Paint } & \multicolumn{6}{|c|}{ Time of exposure $(h)$} \\
\hline & \multicolumn{2}{|l|}{1000} & \multicolumn{2}{|l|}{1540} & \multicolumn{2}{|l|}{2600} \\
\hline & Corr $^{\mathrm{a}}$ & Blis $^{\mathrm{a}}$ & Corr $^{\mathrm{a}}$ & Blis $^{\mathrm{a}}$ & Corr $^{\mathrm{a}}$ & Blis $^{\mathrm{a}}$ \\
\hline A & 10 & 10 & 10 & 10 & 10 & $8 \mathrm{D}$ \\
\hline B & 10 & 10 & 9S & 10 & $8 \mathrm{~S}$ & $8 \mathrm{D}$ \\
\hline $\mathrm{C}$ & 10 & 10 & $9 \mathrm{P}$ & 10 & $8 \mathrm{P}$ & $8 \mathrm{M}$ \\
\hline D & $9 \mathrm{P}$ & $8 \mathrm{~F}$ & $9 \mathrm{P}$ & $8 \mathrm{~F}$ & $9 \mathrm{P}$ & $6 \mathrm{~F}$ \\
\hline $\mathrm{E}$ & $9 \mathrm{P}$ & 10 & $8 S$ & $6 \mathrm{~F}$ & $8 \mathrm{~S}$ & $6 \mathrm{~F}$ \\
\hline $\mathrm{F}$ & $9 \mathrm{P}$ & 10 & $9 \mathrm{P}$ & 10 & $9 \mathrm{P}$ & $8 \mathrm{~F}$ \\
\hline
\end{tabular}

a Corr, corrosion degree (ASTM 610); Blis, blistering degree (ASTM D714).

After 1540 h, E also blistered; only the control panels did not present corrosion. This results confirmed the ones obtained in the polarization curves, indicating that the silane film do not have protective properties.

When $2600 \mathrm{~h}$ of exposure elapsed, the control panels still did not present corrosion and it was overall the one with the better protective behavior. However, the blistering degree was important (small size of blisters but with a high frequency, 8D). The other painted panels presented corrosion points and blisters. Paints $D$ and E presented few medium size blisters (6), while paints B, C and $\mathrm{F}$ presented very small blisters with high, medium and few frequency, respectively.

These results can be seen in Table 2 .

In Table 3, the evaluation of the damaged area can be seen. The mean creepage from the scribe was less than $1.0 \mathrm{~mm}$ along the test, in every case. However, only protective system B and F kept the

Table 3

Evaluation of the creepage around the scribe of painted panels after the salt spray test (ASTM B117).

\begin{tabular}{llll}
\hline Paint & \multicolumn{2}{l}{ Time of exposure $(\mathrm{h})$} & \\
\cline { 2 - 4 } & 1000 & 1540 & 2600 \\
\hline A & 9 & 9 & 8 \\
B & 9 & 9 & 9 \\
C & 8 & 8 & 8 \\
D & 8 & 8 & 8 \\
E & 9 & 8 & 8 \\
F & 9 & 9 & 9 \\
\hline
\end{tabular}

Table 4

Rusting (ASTM D610), blistering (ASTM D714) degrees of painted panels exposed to the humidity chamber (ASTM D2247).

\begin{tabular}{|c|c|c|c|c|c|c|c|c|}
\hline \multirow[t]{3}{*}{ Paint } & \multicolumn{8}{|c|}{ Time of exposure (h) } \\
\hline & \multicolumn{2}{|l|}{600} & \multicolumn{2}{|l|}{1000} & \multicolumn{2}{|l|}{1540} & \multicolumn{2}{|l|}{2600} \\
\hline & Corr $^{\mathrm{a}}$ & Blis $^{\mathrm{a}}$ & Corr $^{\mathrm{a}}$ & Blis $^{a}$ & Corr $^{\mathrm{a}}$ & Blis $^{\mathrm{a}}$ & Corr $^{\mathrm{a}}$ & Blis $^{\mathrm{a}}$ \\
\hline A & 10 & $8 \mathrm{D}$ & 10 & $8 \mathrm{D}$ & 10 & $8 \mathrm{D}$ & 10 & $6 \mathrm{D}$ \\
\hline B & 10 & $8 \mathrm{D}$ & 10 & $8 \mathrm{D}$ & 10 & $8 \mathrm{D}$ & 10 & $6 \mathrm{D}$ \\
\hline C & $9 \mathrm{P}$ & $8 \mathrm{D}$ & $9 P$ & $8 \mathrm{D}$ & $9 P$ & $8 \mathrm{D}$ & 9P & $6 \mathrm{D}$ \\
\hline D & 10 & $8 \mathrm{D}$ & 10 & $8 \mathrm{D}$ & 10 & $8 \mathrm{D}$ & $9 P$ & $8 \mathrm{D}$ \\
\hline E & 10 & $8 \mathrm{D}$ & 10 & $8 \mathrm{D}$ & 10 & $8 \mathrm{D}$ & $9 \mathrm{P}$ & $8 \mathrm{D}$ \\
\hline $\mathrm{F}$ & - & - & - & - & - & - & - & - \\
\hline
\end{tabular}

a Corr, corrosion degree (ASTM 610); Blis, blistering degree (ASTM D714).

creep under $0.5 \mathrm{~mm}$ after $2600 \mathrm{~h}$, better results than the control paint.

When the paint around the damaged area was removed by immersion of the panels in $10 \%$, by volume, of acetic acid solution at $50^{\circ} \mathrm{C}$, the attack underneath the paint was important in the case of the control panels A (Fig. 8a) and C (Fig. 8b). In the cases of panels B and $\mathrm{D}$, the corrosion degree was less important than in the control. The underneath steel was almost undamaged in the case of panels E (Fig. 8c) and F.

In the humidity chamber the painted panels presented blisters after $600 \mathrm{~h}$, quite small and very frequent. However, the blistering degree was almost constant up to the end of the test. Corrosion appeared in the case of C, D and E, after 600 in the first case and after $2600 \mathrm{~h}$ in the other cases. Panels F blistered prematurely and after $168 \mathrm{~h}$ small but quite frequently blisters appeared, corrosion signs could also be seen and, taking into account these results, the panels were removed from the chamber (Table 4).

\subsubsection{Adhesion}

The incorporation of glymo in the pretreatment or in the paint did not enhance dry adhesion of the paint to the substrate; the adhesion values were the highest possible reached by this test $(5 \mathrm{~B})$ and it did not diminish with the exposure of the panels to the salt spray chamber. Only paint D, with extra epoxy resin loss its adhesion to the substrate almost completely after $1000 \mathrm{~h}$ of test (qualification 1B, 35-65\% of the paint area removed).

\section{Discussion}

The presence of glymo in the metal-paint interface and the excess of epoxy resin increased the tendency of the substrate to corrode. The blistering degree was diminished comparing with the control, except when glymo alone was employed as pretreatment. Moreover, the protection performance is also diminished by the silane and a dopant must be added in order to protect steel as the control paint does. This might be due to the fact that the presence of glymo by itself does not enhance paint adhesion as the sandblasted produce a degree of roughness and cleanness good enough.

The performance of the different pretreatment in the damaged area could be explain taking into account that oxane bonds (Metal-O-Si), formed on the interface metal-silane, are hydrolysable, but the resulting Metal-OH and HOSi groups condense readily to reform the oxane bond, using the reaction to relax stresses across the interface [30]. According to this, the pretreated panels can afford the entrance of water across the interface by breaking and unbreaking of silane-metal bonds. Moreover, if the silane is doped, the dopant is dissolved in the interface and might act as corrosion inhibitor on demand in the aggressive media until the damage is repaired. 

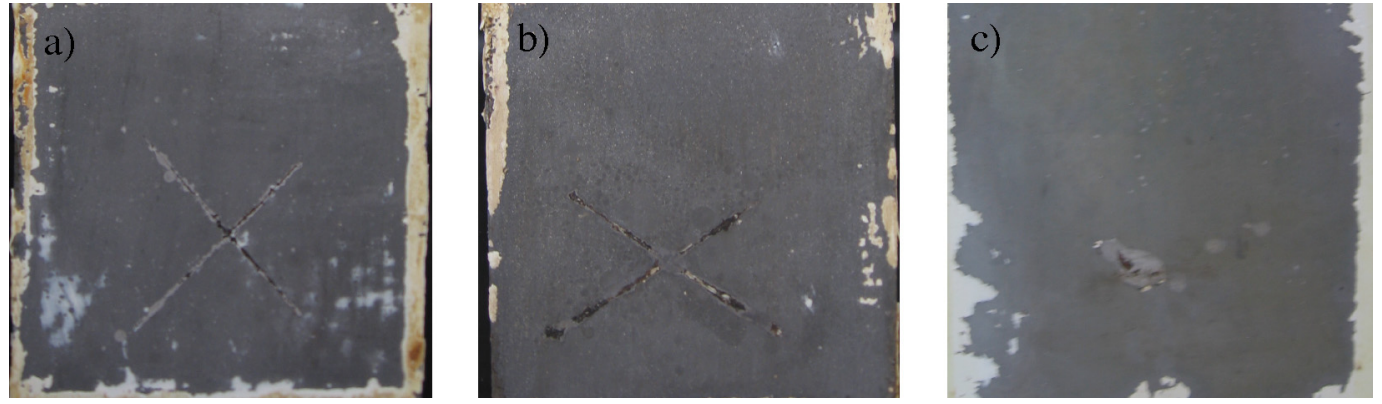

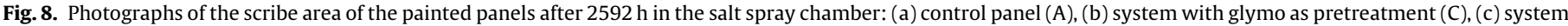
doped with sodium acid phosphate (E).

\section{Conclusions}

- The film formed on the steel by hydrolyzed $\gamma$ glycidoxypropyltrimethoxysilane followed the roughness of the substrate and it did not presente major inhomogeneities, even when dopants as sodium phosphate or sodium benzoate were added.

- The incorporation of $\gamma$-glycidoxypropyltrimethoxysilane as pretreatment or in paint formulation did not enhance paint adhesion in undamaged areas.

- Paints formulated with extra epoxy resin lost their adhesion to the substrate prematurely.

- When the painted area was damaged the incorporation of silane in the paint or the incorporation of sodium benzoate as dopant in the silane pretreatment enhanced the protection compared with the control system. However, the incorporation of $\mathrm{Na}_{2} \mathrm{HPO}_{4}$ did not increase paint protection.

- The silane doped with sodium benzoate failed prematurely in low aggressive media.

\section{Acknowledgments}

The author thanks the Consejo Nacional de Investigaciones Científicas y Técnicas (CONICET), the Universidad Nacional de La Plata (UNLP) and the Comisión de Investigaciones Científicas de la Provincia de Buenos Aires (CICPBA), by the financial support to carry out the present research paper. The author also thanks to Bernardo Browne and Andrés Campbell from Camsi-X for the silane to do this research.

\section{References}

[1] P. Walker, in: A. Pizzi, K.L. Mittal (Eds.), Silane and Other Adhesion Promoter in Adhesive Technology, Taylor \& Francis Group, 2003 (Chapter 10).

[2] F. Eppensteiner, M.R. Jenkins, Chromate conversion coatings, Metal Finishing 97 (January (1 Suppl. (1))) (1999) 494-506.

[3] R. Goyer, Toxic effects of metals, in: Casarett and Doull's Toxicology: The Basic Science of Poisons, first ed., McGraw-Hill, 1999, pp. 691-736.

[4] W.J. van Ooij, D. Zhu, M. Stacy, A. Seth, T. Mugada, J. Gandhi, P. Puomi, Corrosion protection properties of organofunctional silanes - an overview, Tsinghua Sci. Technol. 10 (December (6)) (2005).

[5] B. Chico, J.C. Galván, D. de la Fuente, M. Morcillo, Electrochemical impedance spectroscopy study of the effect of curing time on the early barrier properties of silane systems applied on steel substrates, Prog. Org. Coat. 60 (2007) 45-53.

[6] S.-X. Zheng, J.-H. Li, Inorganic-organic sol gel hybrid coatings for corrosion protection of metals, J. Sol-Gel Sci. Technol. 54 (2010) 174-187.
[7] B. Chico, D. de la Fuente, M.L. Pérez, M. Morcillo, Corrosion resistance of steel treated with different silane/paint systems", J. Coat. Technol. Res. 9 (1) (2012) 3-13.

[8] P. Walker, Organosilanes as adhesion promoters for organic coatings. Part 1 : silanes on the metal surface, J. Oil Col. Chem. Assoc 65 (1992) 415-423.

[9] M. Fedel, M. Olivier, M. Poelman, F. Deflorian, S. Rossi, E.-E. Druart, Corrosion protection properties of silane pre-treated powder coated galvanized steel, Prog. Org. Coat. 66 (2009) 118-128.

[10] N. Zand, M. Mahdavian, Corrosion and adhesion study of polyurethane coating on silane pretreated aluminum, Surf. Coat. Technol. 203 (2009) 1677-1681.

[11] P. Walker, Organosilanes as adhesion promoters for organic coatings. Part 2: silanes in the paint, J. Oil Col. Chem. Assoc. 65 (1992) 415-423.

[12] M. Ferreira, R. Duarte, M. Montemor, A. Simoes, Silanes and rare earth salts as chromate replacers for pre-treatments on galvanised steel, Electrochim. Acta 49 (2004) 2927-2935.

[13] H. Wang, R. Akid, Encapsulated cerium nitrate inhibitors to provide high-performance anti-corrosion sol-gel coatings on mild steel, Corros. Sci. 50 (2008) 1142-1148.

[14] R.L. Twite, G.P. Bierwagen, Review of alternatives to chromate for corrosion protection of aluminum aerospace alloys, Prog. Org. Coat. 33 (1998) 91-100

[15] G. Kong, J. Lu, S. Zhang, C. Che, H. Wu, A comparative study of molybdate/silane composite films on galvanized steel with different treatment processes, Surf. Coat. Technol. 205 (2010) 545-550.

[16] G. Blustein, M.C. Deyá, R. Romagnoli, A.R. Di Sarli, B. del Amo, Improvement of anticorrosive performance of phosphate-based alkyd paints with suitable additives, J. Coat. Technol. Res. 8 (2) (2011) 171-181.

[17] G. Blustein, M.C. Deyá, R. Romagnoli, B. del Amo, Three generations of inorganic phosphates in solvent and water-borne paints: a synergism case, Appl. Surf. Sci. 252 (2005) 1386-1397.

[18] P.R. Roberge, R. Beaudoin, V.S. Sastri, Corros. Sci. 29 (10) (1989) 1231-1233.

[19] J.R. Kearns, J.R. Scully, P.R. Roberge, D.L. Reichert, J.L. Dawson (Eds.), Electrochemical Noise Measurements for Corrosion Applications, ASTM, STP 1277, USA, 1996

[20] R.A. Cottis, Interpretation of electrochemical noise data, Corrosion 57 (3) (2001) 265-285.

[21] F. Huet, Electrochemical noise technique, in: P. Marcus, F. Mansfeld (Eds.) Analytical Methods in Corrosion Science and Engineering, CRC Taylor \& Francis, USA, 2005

[22] S. Mabbutt, D.J. Mills, C.P. Woodcock, Developments of the electrochemical noise method (ENM) for more practical assessment of anti-corrosion coatings, Prog. Org. Coat. 59 (2007) 192-196.

[23] Y.J. Tan, S. Bailey, B. Kinsella, The monitoring of the formation and destruction of corrosion inhibitor films using electrochemical noise analysis (ENA), Corros. Sci. 38 (1996) 1681-1695.

[24] ASTM B 117, Standard practice for operating salt spray (fog) apparatus, ASTM 2009

[25] ASTM D 2247, Standard practice for testing water resistance of coatings in 100\% relative humidity, ASTM, 2011.

[26] ASTM D 610, Standard test method for evaluating degree of rusting on painted steel surfaces, ASTM, 2001.

[27] ASTM D 714, Standard test method for evaluating degree of blistering of paints, ASTM, 2002

[28] ASTM D 1654, Standard test method for evaluation of painted co coated specimens subjected to corrosive environment, ASTM, 1992.

[29] ASTM D 3359, Standard test methods for measuring adhesion by tape test ASTM, 2002.

[30] E. Plueddemann, Silane adhesion promoters in coating, Prog. Org. Coat. 11 (1983) 297-308 